\title{
Interprofessional work in health in the context of the COVID-19 pandemic: a scoping review
}

\author{
O trabalho interprofissional em saúde no contexto da pandemia de COVID-19: revisão de escopo \\ Trabajo interprofesional en salud en el contexto de la pandemia del COVID-19: revisión del alcance
}

How to cite this article:

Fernandes SF, Trigueiro JG, Barreto MAF, Carvalho REFL, Silva MRF, Moreira TMM, Costa MV, Freitas RJM. Interprofessional work in health in the context of the COVID-19 pandemic: a scoping review. Rev Esc Enferm USP. 2021;55:e20210207. https://doi.org/10.1590/1980-220X-REEUSP-2021-0207.

\footnotetext{
Sâmara Fontes Fernandes ${ }^{1}$

(i) Jaira Gonçalves Trigueiro ${ }^{1}$

(iD) Márcio Adriano Fernandes Barreto ${ }^{1}$

(D) Rhanna Emanuela Fontenele Lima de Carvalho ${ }^{1}$

(iD) Maria Rocineide Ferreira da Silva ${ }^{1}$

(D) Thereza Maria Magalhães Moreira ${ }^{1}$

iD Marcelo Viana da Costa ${ }^{2}$

(iD) Rodrigo Jácob Moreira de Freitas ${ }^{3}$

${ }^{1}$ Universidade Estadual do Ceará, Departamento de Enfermagem, Fortaleza, CE, Brazil.

${ }^{2}$ Universidade Federal do Rio Grande do Norte, Escola Multicampi de Ciências Médicas, Departamento de Medicina, Caicó, RN, Brazil.

${ }^{3}$ Universidade do Estado do Rio Grande do Norte, Departamento de Enfermagem, Pau dos Ferros, RN, Brazil.
}

\begin{abstract}
Objective: to map the scientific production on interprofessional relationships in health in the first year of the COVID-19 pandemic. Method: this is a scoping review performed in PubMed, Scopus, LILACS, CINAHL, Web of Science, Google Scholar and Science Direct databases, covering the period of publication in 2020, using the acronym PCC (Population = health professionals; Concept $=$ interprofessional relationships; Context $=$ health services) and respective search strategies. Results: fourteen scientific articles were selected and the content discussed in the manuscripts was standardized, analyzed and organized into categories of affinities and similarities of their results: 1 - Interprofessional collaboration; 2 - Collaborative practice; 3 -Interprofessional work; 4 -Interactive and interprofessional learning. Conclusion: the pandemic demanded quick and effective responses that were only possible through collaboration and interprofessionalism dimensions. Interprofessional work in health during the first year of the COVID-19 pandemic confirms the importance of interprofessional work and its dimensions for the provision of more comprehensive, resolute and safer health services.
\end{abstract}

\section{DESCRIPTORS}

Interprofessional Relations; Health Personnel; Pandemics; Coronavirus Infections; Crew Resource Management, Healthcare. 


\section{INTRODUCTION}

In the COVID-19 pandemic context, new health needs and practices were highlighted, increasing the charge, workload and complexity of health care, in addition to creating a scenario of uncertainty and vulnerability, causing high levels of stress and anxiety among health professionals ${ }^{(1)}$. Thus, shared care is needed between the health team, which must act with integration and collaboration, with articulated actions and a practice directed to the health needs of patients, respecting their autonomy and leading role in the health-disease process; that is why interdisciplinary dialogues are essential to expand the response capacity ${ }^{(2-3)}$.

Interprofessional collaborative practices have been presented in the pandemic as an important tool for work reorganization, which helps in the construction of a new care model that must be accurate, effective and safe ${ }^{(4)}$. Therefore, interprofessional teams' work in the care for patients with COVID-19 has been positively influencing health practices, improving communication, interaction, cooperation and decision-making among the health team, reducing conflicts and incorporating greater flexibility and encouraging interprofessional education that qualifies professionals to work with complex demands and with safer, more satisfactory and better quality practices ${ }^{(5-6)}$.

Health services that work with interprofessional teams, encouraging the development of collaborative and educational practices in the pandemic, demonstrated better organizational and coping skills, in addition to having better indicators ${ }^{(5)}$. It is evident that there is a need to restructure the operational flows of health services, striving for patient safety and service quality, helping to build comprehensive care in health care ${ }^{(3)}$.

Therefore, the interprofessional role in health is necessary in the practice of care, especially during the care for patients with COVID-19, due to its complexity and lack of information with scientific evidence. However, there is a lack of studies that address the issue, and no scoping and systematic review of interprofessional work in the pandemic context has been identified. Given the above, the question is: what scientific evidence is contained in the scientific production on interprofessional work in health services during the first year of the COVID-19 pandemic? In order to answer this question, the objective of this study was to map the scientific production about interprofessional work in health, in the first year of the COVID-19 pandemic.

\section{METHOD}

\section{Study Design}

The study was designed as a scoping review (or scoping study), built according to the method recommended by the Joanna Briggs Institute ${ }^{(7)}$, in accordance with the theoretical framework proposed by Arksey and O’Malley ${ }^{(8)}$. This type of research allows the mapping of scientific production, highlighting relevant studies in the area and identifying possible knowledge gaps that can be deepened in further studies ${ }^{(7)}$. The study elaboration followed the steps as follows: 1 - Problem issue identification; 2 - Inclusion criteria; 3 - Research strategies; 4 - Extraction of results; 5 - Presentation of results ${ }^{(7-8)}$. We also considered the recommendations of the Prisma Extension for Scoping Reviews (Primas-ScR) ${ }^{(9)}$ and Rethlefsen ${ }^{(10)}$.

\section{Protocol and Registration}

The protocol used in the study was prospectively designed and registered with the Open Science Framework on December 12, 2020 (osf.io/nzef5).

\section{ReseARCh Question}

The research question of this study was constructed according to the mnemonic combination PCC (P - Population (Population) - Health professionals; $\mathrm{C}$ - Concept (Concept) Interprofessional relationships; $\mathrm{C}$ - Context (Context) - Health services), the following problem question being defined: what is known about interprofessional work in health services during the first year of the COVID-19 pandemic?

\section{InCLUSION CRITERIA}

To refine the research, the following inclusion criteria were established: 1 - Original articles that have been developed with health professionals working in the care of people with COVID-19 (Population) and that address the interprofessional relationships between health professionals (Concept) in the health services in the first year of the COVID-19 pandemic, 2020 (Context); 2 - Full articles indexed in selected databases; 3 - Available in Portuguese, English or Spanish; 4 - Published during 2020 (January to December) - this time frame was used because it is the period of validity of the first year of the COVID-19 pandemic. Studies that dealt with editorials and opinion articles, which were developed exclusively in the educational sector and which did not include the guiding question, were excluded.

\section{Search Strategy}

To identify articles relevant to the topic, the following bibliographic databases searched from Capes Journal were used: PubMed, Scopus, CINAHL, Web of Science, Latin American and Caribbean Health Sciences Literature (LILACS), Google Scholar and Science Direct. Moreover, a reverse search of the literature reference list included and listed in the study was also performed to retrieve pertinent articles. Articles published from January 1 to December 31, 2020 were searched.

Descriptors recommended by the Medical Subject Headings (MeSH) and/or the Health Sciences Descriptors (DeCS) (in Portuguese, English and Spanish) were considered: 1 - Relaçôes Interprofissionais/Interprofessional Relations/ Relaciones Interprofesionales; 2 - Pessoal de Saúde/Health Personnel/ Personal de Salud; 3 - Pandemias/Pandemics/Pandemias; 4 - Infeç̧ôes por Coronavirus/Coronavirus Infections/Infecciones por Coronavirus, also including the keywords Interprofessionality, collaborative practice and COVID-19, aiming to expand electronic research, considering the Boolean operators AND and OR. The search strategy adopted in each database described in Chart 1. It is worth noting that Google Scholar used only one search key because it dealt with its complete composition (Interprofessional Relations OR Interprofessionality AND Health Personnel AND Pandemics AND COVID-19 OR Coronavirus Infections) and by the number of publications found. 
Chart 1 - Databases, search strategies - Mossoró, RN, Brazil, 2020.

\begin{tabular}{|c|c|}
\hline Databases & Search strategy \\
\hline \multirow{2}{*}{ PubMed } & Interprofessional Relations OR interprofessionality AND Health Personnel AND Pandemics AND COVID-19 \\
\hline & Interprofessional Relations OR collaborative practice AND Health Personnel AND Pandemics AND COVID-19 \\
\hline \multirow{2}{*}{ CINHAL } & Interprofessional Relations OR interprofessionality AND Health Personnel AND Pandemics AND COVID-19 \\
\hline & Interprofessional Relations OR collaborative practice AND Health Personnel AND Pandemics AND COVID-19 \\
\hline \multirow{2}{*}{ LILACS } & Interprofessional Relations OR interprofessionality AND Health Personnel AND Pandemics AND COVID-19 \\
\hline & Interprofessional Relations OR collaborative practice AND Health Personnel AND Pandemics AND COVID-19 \\
\hline \multirow{2}{*}{ Scopus } & Interprofessional Relations OR interprofessionality AND Health Personnel AND Pandemics AND COVID-19 \\
\hline & Interprofessional Relations OR collaborative practice AND Health Personnel AND Pandemics AND COVID-19 \\
\hline \multirow{2}{*}{ Web of Science } & Interprofessional Relations OR interprofessionality AND Health Personnel AND Pandemics AND COVID-19 \\
\hline & Interprofessional Relations OR collaborative practice AND Health Personnel AND Pandemics AND COVID-19 \\
\hline Google Scholar & Interprofessional Relations OR interprofessionality AND Health Personnel AND Pandemics AND COVID-19 OR Coronavirus Infections \\
\hline \multirow{2}{*}{ Science Direct } & Interprofessional Relations OR interprofessionality AND Health Personnel AND Pandemics AND COVID-19 \\
\hline & Interprofessional Relations OR collaborative practice AND Health Personnel AND Pandemics AND COVID-19 \\
\hline
\end{tabular}
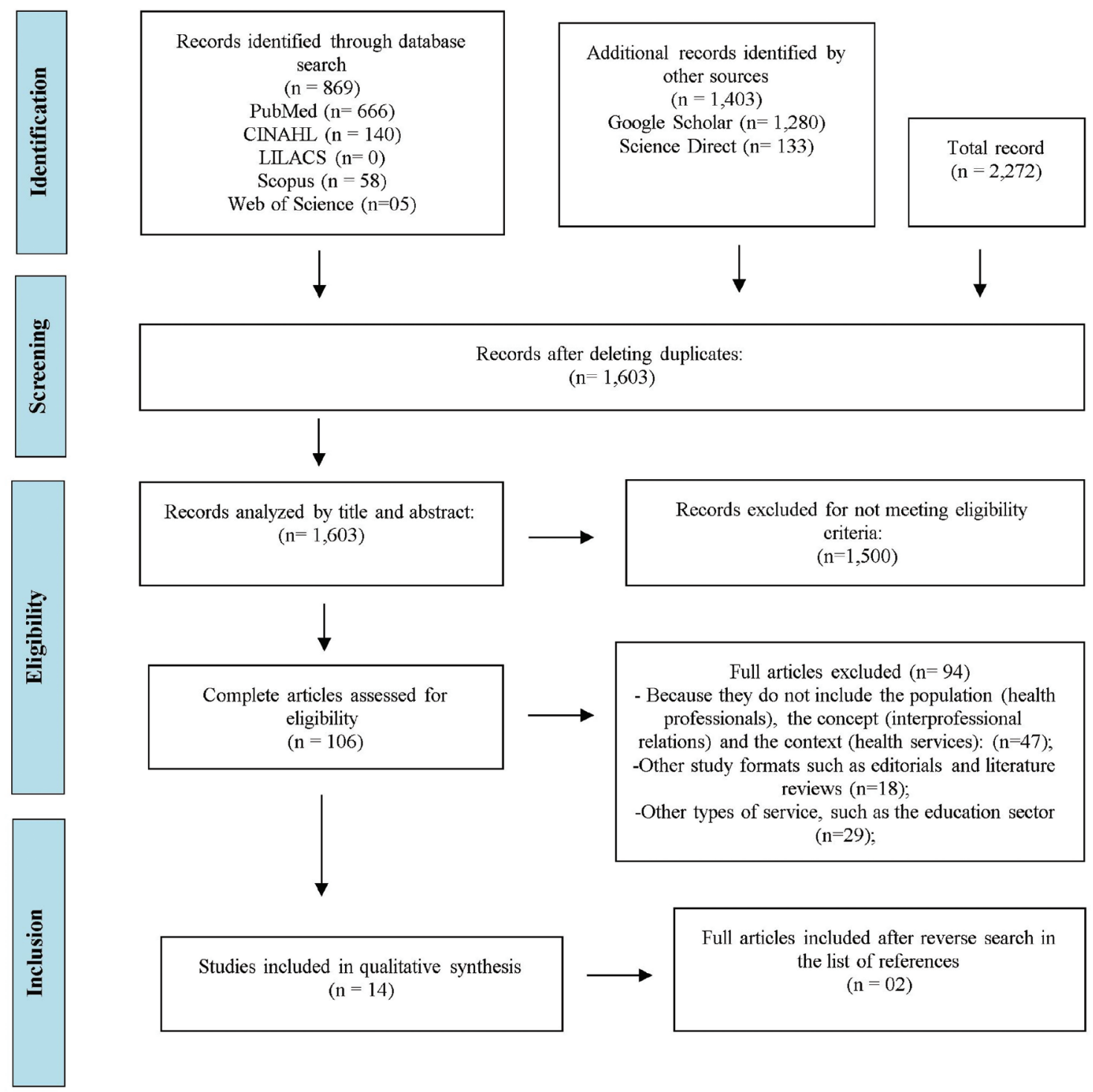

Figure 1 - Flow diagram of the review article selection process according to PRISMA-ScR ${ }^{(9)}, 2020$ and Rethlefsen ${ }^{(10)}, 2021$. 
References from selected articles were also analyzed to identify new studies for inclusion. The studies were pre-selected from titles and abstracts right after reading the entire bibliography, which defined the final sample of the research. To reaffirm the research consistency, screening, data extraction and analysis of the bibliographic sample were carried out by two reviewers independently and differences were resolved by a third reviewer.

\section{EXtraction of Results}

To perform data extraction, a structured instrument in Microsoft Excel 2019 was used, which allowed identifying essential elements of the study, such as author, title, year of publication, country of study, journal, language, database, study objective, participants, study relevance, identified interprofessional relationships, limitations and impacts in health practice.

\section{Presentation of Results}

After extracting the data, the findings were consolidated in a table with the main study characteristics included in the research, presenting an overview of all the material used and its importance for the topic. A synthesis of results, recommendations and practices was also carried out, which were discussed and grouped by content similarity. The categories were analyzed using thematic analysis.
The research waived submission and approval by an Institutional Review Board, as it used only secondary data from literature, respecting Resolution 466/12 of the Brazilian National Health Council (Conselho Nacional de Saúde) with regard to analysis and sharing of results.

\section{RESULTS}

According to the electronic search, 2,272 scientific articles were identified in the databases and 669 duplicated were removed, resulting in 1,603 articles selected for reading of titles and abstracts. According to the two reviewers who independently analyzed the scientific materials, 106 articles were selected according to titles and abstracts and included for full reading; of these, 12 included the PCC. A reverse search was also carried out in the reference list of the 12 selected articles, including 02 articles that answered the problem question and were relevant to the study. Therefore, the final sample consisted of 14 scientific articles, shown in Figure 1. It is noteworthy that no manual, monograph, dissertation or thesis were found in the electronic search.

In order to facilitate the presentation of data extracted from the articles, Chart 2 included study characterization, including information such as author, title, country, language and methodological approach.

Chart 2 - Characterization of articles included in this scoping review - Mossoró, RN, Brazil, 2020.

\begin{tabular}{|c|c|c|c|}
\hline Author & Title & Country/Language & Approach \\
\hline Khan, JA., Kiani, $\mathrm{M}^{(11)}$. & $\begin{array}{l}\text { Impact of multi-professional simulation-based training on perceptions of safety } \\
\text { and preparedness among health workers caring for coronavirus disease } 2019 \\
\text { patients in Pakistan }\end{array}$ & Pakistan/English & Quantitative \\
\hline $\begin{array}{l}\text { Archbal-Pannone, LR. } \\
\text { et } \mathrm{al}^{(12)} \text {. }\end{array}$ & $\begin{array}{l}\text { COVID-19 Collaborative Model for an Academic Hospital and Long-Term Care } \\
\text { Facilities }\end{array}$ & USA/English & Qualitative \\
\hline $\begin{array}{l}\text { Sarver, WL., Seabold, } \\
\quad \text { K. \& Kline, } M^{(13)} \text {. }\end{array}$ & $\begin{array}{l}\text { Shadowing to Improve Teamwork and Communication: A Potential Strategy } \\
\text { for Surge Staffing }\end{array}$ & USA/English & Qualitative \\
\hline Meisner, BA. et $\mathrm{al}^{(14)}$. & $\begin{array}{l}\text { The need for interdisciplinary and collaborative approaches to assess the impact } \\
\text { of COVID-19 on seniors and aging: Joint statement by ACG/CAG and RCV/CJA }\end{array}$ & Canada/English & Qualitative \\
\hline Lingum, NR. et $\mathrm{al}^{(1)}$. & $\begin{array}{l}\text { Building Long-Term Care Staff Capacity During COVID-19 Through Just-in- } \\
\text { Time Learning: Evaluation of a Modified ECHO Model }\end{array}$ & Canada/English & $\begin{array}{l}\text { Mixed method } \\
\text { (quantitative and } \\
\text { qualitative) }\end{array}$ \\
\hline Natale, JE. et al ${ }^{(15)}$. & $\begin{array}{l}\text { Interprofessional/interdisciplinary teamwork during the early COVID-19 } \\
\text { pandemic: experience from a children's hospital within an academic health } \\
\text { center }\end{array}$ & USA/English & Qualitative \\
\hline Stifter, J. et $\mathrm{al}^{(5)}$. & $\begin{array}{l}\text { A short report on an interprofessional mobilizer team: innovation and impact } \\
\text { during the COVID-19 pandemic. }\end{array}$ & USA/English & Qualitative \\
\hline Belarmino, AC. et $\mathrm{al}^{(6)}$. & Práticas colaborativas em equipe de saúde diante da pandemia de COVID-19 & Brazil/Portuguese & Qualitative \\
\hline Hales, P. et al ${ }^{(16)}$. & A case study of a collaborative allied health and nursing crisis response. & United Kingdom/English & Qualitative \\
\hline $\begin{array}{l}\text { Goldman, J. \& } \\
\text { Xyrichis, } \mathrm{A}^{(17)} \text {. }\end{array}$ & Interprofessional working during the COVID-19 pandemic: sociological insights & United Kingdom/English & Qualitative \\
\hline Carenzo, L. et al ${ }^{(18)} * *$ & $\begin{array}{l}\text { Hospital surge capacity in a tertiary emergency referral centre during the } \\
\text { COVID-19 outbreak in Italy }\end{array}$ & Italy/English & Qualitative \\
\hline $\begin{array}{l}\text { Azizoddin, DR. } \\
\text { et } \mathrm{al}^{(19)} *^{*}\end{array}$ & $\begin{array}{l}\text { Bolstering clinician resilience through an interprofessional, web-based nightly } \\
\text { debriefing program for emergency departments during the COVID-19 pandemic }\end{array}$ & USA/English & Qualitative \\
\hline $\begin{array}{l}\text { Amy Tronnier, BA. } \\
\text { et al }\end{array}$ & $\begin{array}{l}\text { COVID-19 Intubation Safety: A Multidisciplinary, Rapid-Cycle Model } \\
\text { of Improvement }\end{array}$ & USA/English & $\begin{array}{l}\text { Mixed method } \\
\text { (quantitative and } \\
\text { qualitative) }\end{array}$ \\
\hline $\begin{array}{l}\text { Caneppele, } \mathrm{AH} . \\
\quad \text { et } \mathrm{al}^{(21)}\end{array}$ & $\begin{array}{l}\text { Colaboração interprofissional em equipes da rede de urgência e emergência na } \\
\text { pandemia da COVID-19 }\end{array}$ & Brazil/Portuguese & Quantitative \\
\hline
\end{tabular}

* Articles included in reverse search. 
Chart 3 - Main results of the articles included in this scoping review and their impact on health care practice - Mossoró, RN, Brazil, 2020.

\begin{tabular}{|l|}
\hline Objective \\
\hline Assess the perceptions of healthcare workers \\
caring for patients with COVID-19 about \\
patient safety before and after a simulation- \\
based training held at the Combined Military \\
Hospital Landi Kotal Cantt in Pakistan ${ }^{(11)}$.
\end{tabular}

Report on the creation and implementation of the Geriatric Engagement and Resource Integration in Post-Acute and Long-Term Care Facilities and its contributions in consulting, counseling and collaboration with post-acute and long-term care institutions (PA/LTC) for the elderly during the COVID-19 pandemic ${ }^{(12)}$.

Assess the ability to understand and collaborate in the professional experiences obtained from the "Walk a Mile in My shoes" program. The program was developed in a health unit, with the objective of increasing the efficiency of the models of care delivery, teamwork and communication between nursing units ${ }^{(13)}$.

Reflect on the adoption of interdisciplinary approaches in responding to COVID-19 and the need for collaborative practices between institutions that develop elder care in Canada ${ }^{(14)}$.

Determine the effectiveness of just-in-time learning in the development of health best practices by staff and residents in elderly care in long-term institutions during the pandemic ${ }^{(1)}$

Describe the experience of a children's hospita in an academic health center that developed an interprofessional and interdisciplinary teamwork during the beginning of the COVID-19 pandemic ${ }^{(15)}$

Report the experience regarding the implementation of a mobilizing team in a large hospital that works in an interprofessional way in fighting COVID-19 ${ }^{(5)}$.

Report the experience of collaborative practices in fighting the COVID-19 pandemic in Emergency Care Units in Fortaleza, Ceará, in the first half of $2020^{(6)}$.

Assess the contributions of interprofessional work in a UK specialist hospital as part of a crisis response in critical care ${ }^{(16)}$.

\section{Main results}

It reaffirms the importance and need for professional qualification in simulation service for health professionals or general and administrative services. These trainings can involve assistance professionals and those who provide indirect services in health services.

It recognizes the need for collaboration between health professionals and various health institutions, as well as with educational institutions, to strengthen the articulation, qualification and responsiveness of both institutions to fight the COVID-19 pandemic.

It strengthens the assumption that teamwork and communication are instruments that qualify care and ensure patient safety. In addition to suggesting cross-training as a healthy strategy for the qualification of professionals during the COVID-19 pandemic, helping to prepare for emergency care in COVID-19 and the possible relocation of personnel. It emphasizes the development of inservice training, in which health professionals are temporarily allocated to other services to accompany professional colleagues and learn about that service so that they can apply in their workplace.

It understands the COVID-19 pandemic as a natura laboratory that highlights the elderly's health needs, cared for by family members or in long-term care facilities. It reaffirms that the elderly is a vulnerable group due to pre-existing health needs and those resulting from the pandemic.

It reaffirms the existence of an eminent need for training in gerontology applied to COVID-19, aimed at qualifying health teams and everyone involved in elder care so that this assistance is strengthened.

It highlights the need for continuing education as a crucial and strategic instrument in fighting the COVID-19 pandemic, which manages to reformulate and adapt practices to the new health situation and needs, with an emphasis on the importance of collaboration between institutions.

Collaborative relationships that transform care practices must be expanded and strengthened at all times, especially in times of crisis.

IP/ID (Interprofessional and Interdisciplinary) team were formed to structurally reorganize a pediatric hospital, develop safety and care protocols, and train employees in the care of patients with COVID-19, positively impacting health services and qualifying care for patients with COVID-19.

The presence of a mobilizing team is efficient in the restructuring of healthcare practices in the hospital, as they work from collaboration and communication, creating partnerships, strengthening the bond between the team and providing an opportunity for an interprofessional performance scenario.

It reaffirms that interprofessional and collaborative health team's work has an impact on improving quality of care in light to mild and severe conditions of the disease and strengthens health care.

The team created to fight the COVID-19 pandemic trained professionals who were relocated to work in Intensive Care Units, mainly for the prone position and cardiopulmonary resuscitation (CPR).

\section{Implications for practice}

Simulation-based training in hospital environments with the healthcare team is a strategy for strengthening and transforming healthcare practices. The strategy improved the quality and safety of team care for patients with COVID-19.

It was found that a health team's work in an interprofessional and collaborative perspective directly impacts the quality of care provided to the population, specifically in elder care.

Collaboration between professionals and institutions is transforming for health care, expanding the reach, impact and organization of services, minimizing adverse events and qualifying the care provided.

It recognizes that in services where teamwork is collaborative, there are lower mortality rates, fewer adverse events, lower patient injury rate, better quality of care, greater patient and worker satisfaction.

Collaborative teamwork, communication and in service training are used as working tools that help build a collaborative unit and implement a new model of care, which needs to be fast, effective and safe, as in the COVID pandemic-19.

The interdisciplinary action between health teams, caregivers, universities and family, in a collaborative perspective, qualifies elder care and is crucial in reducing illness and death rates, in addition to preventing diseases resulting from the pandemic and its social isolation.

Overall, it increases the confidence and comfort levels of health professionals working with older adults suspected of or diagnosed with COVID-19.

Experience points to a quick response of the service to the COVID-19 pandemic, where the IP/ ID teams play a strategic role in hospital's actions. Collectively identified the unique and innovative needs and approaches that transcended traditional boundaries and frameworks to respond to the COVID-19 pandemic.

The interprofessional approach facilitated better communication between professionals who are led by peers as team members moved through units and interacted with frontline providers and support staff.

The development of collaborative practices in interprofessional teams contributed to strengthening communication within the health team and enabled interaction through the construction of care and care flows, training videos on social networks and applications, as well as training simulations and meetings to define consensus.

The study identified that the presence of the ECT team is transformative for other health professionals who have no experience in critical care, as they feel supported and to safe, reducing their stress levels and improving their response experience to crisis.

continue.. 
...continuation

\begin{tabular}{|c|c|c|}
\hline Objective & Main results & Implications for practice \\
\hline $\begin{array}{l}\text { Address sociological theories that can provide } \\
\text { guidance for experiments on the significance } \\
\text { and impact of the COVID-19 pandemic in } \\
\text { interprofessional practice }{ }^{(17)} \text {. }\end{array}$ & $\begin{array}{l}\text { It identifies the importance of information-sharing } \\
\text { approaches required by the urgency of the situation } \\
\text { and physical distancing measures in times of the } \\
\text { COVID-19 pandemic. } \\
\text { It reaffirms that professional research and education } \\
\text { communities need to work collaboratively to } \\
\text { reflect on the changes in society resulting from } \\
\text { the pandemic and its current needs, in order to } \\
\text { transform health practices. }\end{array}$ & $\begin{array}{l}\text { It reaffirms the need for interprofessional interactions } \\
\text { at the level of daily practice, as a transforming } \\
\text { element of health care. }\end{array}$ \\
\hline $\begin{array}{l}\text { Report the experience and in-service training } \\
\text { in the reception, assessment and intensive } \\
\text { care areas from an interprofessional and } \\
\text { collaborative perspective in hospitals in Italy } \\
\text { that reorganized themselves better in the face } \\
\text { of the COVID-19 pandemic, expanding their } \\
\text { response to the crisis }{ }^{(18)} \text {. }\end{array}$ & $\begin{array}{l}\text { It recognizes interprofessional team's work as an } \\
\text { important element in the reorganization of health } \\
\text { services, supporting more efficiently planning and } \\
\text { new practices in all sectors of the hospital during } \\
\text { the pandemic period, acting with a common goal: } \\
\text { quality patient care and hospital safety. }\end{array}$ & $\begin{array}{l}\text { Health teams' work, from an interprofessional } \\
\text { perspective, in various sectors and health services, } \\
\text { has helped in the restructuring of health services, } \\
\text { increasing their capacity to face the health crisis. }\end{array}$ \\
\hline $\begin{array}{l}\text { Report the experience of developing an } \\
\text { interprofessional tele-debriefing project, in } \\
\text { order to improve the quality of service, reinforce } \\
\text { resilience, while aiming at the well-being of all } \\
\text { involved and process improvements }{ }^{(19)} \text {. }\end{array}$ & $\begin{array}{l}\text { An interprofessional team implemented an optional } \\
\text { web-based debriefing program in response to } \\
\text { the COVID-19 pandemic. Debriefer provided } \\
\text { supportive reflections and allowed colleagues to } \\
\text { connect through shared experiences. }\end{array}$ & $\begin{array}{l}\text { This program reinforced communication and } \\
\text { interprofessional support while improving } \\
\text { operations related to health care at the hospital. } \\
\text { Debriefing fostered cross-professional discussions } \\
\text { that were summarized in helpful feedback } \\
\text { and allowed administrative leaders to instigate } \\
\text { noticeable changes to COVID-19's pandemic- } \\
\text { fighting procedures/operations. }\end{array}$ \\
\hline $\begin{array}{l}\text { Describe a tertiary care model centered on } \\
\text { rapid cycle improvements and real-time gap } \\
\text { analysis to track adherence to intubation } \\
\text { safety in COVID-19 protocols to create a } \\
\text { quality improvement framework to ensure safe } \\
\text { practices for intubation providers }{ }^{(20)} \text {. }\end{array}$ & $\begin{array}{l}\text { Through the formation of a multidisciplinary team } \\
\text { responsible for monitoring the safety of intubation } \\
\text { that works in the health service with an Intubation } \\
\text { Safety Checklist, a standardized documentation } \\
\text { template for intubations, real-time feedback, and } \\
\text { weekly staff meetings to review data and implement } \\
\text { improvements, and assist professionals who perform } \\
\text { these procedures in practice. }\end{array}$ & $\begin{array}{l}\text { The services were able to strengthen care protocols } \\
\text { in practice with recommendations and assessments } \\
\text { of procedures, strengthening them, identifying flaws } \\
\text { and correcting them immediately, providing support } \\
\text { to professionals. In addition to identifying errors in } \\
\text { real time and supporting the training of healthcare } \\
\text { students such as medical residents. }\end{array}$ \\
\hline $\begin{array}{l}\text { Comparatively analyze the interprofessional } \\
\text { collaboration in urgency and emergency teams } \\
\text { before and after the first death from COVID-19 } \\
\text { in Brazil }{ }^{(21)} \text {. }\end{array}$ & $\begin{array}{l}\text { The study was carried out with two groups of } \\
\text { health professionals, in order to measure the } \\
\text { interprofessional collaboration between the teams } \\
\text { at different times: } 1^{\text {st }} \text { moment before the first death } \\
\text { from COVID and } 2^{\text {nd }} \text { time after the first death from } \\
\text { COVID. When comparing the mean scores of the } \\
\text { factors between the two groups, it was noticed } \\
\text { that the mean scores for partnership, cooperation } \\
\text { and coordination were higher in the second group } \\
\text { (after death), when compared in relation to the type } \\
\text { of secondary and tertiary service. Therefore, the } \\
\text { application of AITCS II proved to be relevant for } \\
\text { identifying the constructs that require strengthening } \\
\text { in the context of interprofessional collaboration, } \\
\text { through partnership, cooperation and coordination } \\
\text { dimensions. } \\
\text { The study recognizes and reaffirms that teamwork } \\
\text { and interprofessional collaboration are important } \\
\text { strategies in dealing with the pandemic and in } \\
\text { making shared decisions. }\end{array}$ & $\begin{array}{l}\text { It was identified that interprofessional collaboration, } \\
\text { through partnership, cooperation and coordination } \\
\text { dimensions influence the quality of care, improving } \\
\text { health indicators and reducing levels of illness by } \\
\text { professionals. } \\
\text { The emergency network teams showed positive } \\
\text { trends in interprofessional collaboration. }\end{array}$ \\
\hline
\end{tabular}

From the chart shown above, it is clear that most publications were in English and with a qualitative approach, suggesting a scientific internationalization about the dissemination of knowledge related to the COVID-19 pandemic.

The research development scenarios were medium and high complexity hospitals, specific hospital sectors, long-term institutions and universities in collaborative action with health services. Thus, it calls our attention to the fact that no studies were found within the scope of Primary Health Care (PHC), as it is responsible for prevention and health promotion actions, essential for controlling and combatting various diseases, including COVID-19.

Regarding the content discussed in the manuscripts, there was uniformity in the published information, which was analyzed and organized into categories by content similarity, namely: 1 - Interprofessional collaboration; 2 - Collaborative practice; 3 - Interprofessional work; 4 - Interactive and interprofessional learning.

Considering the importance of the evidence found and its relationship with the research problem and objective, main results and their impact(s) on health care practice were organized in Chart 3 above.

\section{DISCUSSION}

The results referred to in this scoping review were organized by content similarity in the categories Interprofessional collaboration, Collaborative practice, Interprofessional work and Interactive and interprofessional learning, as they are crucial 
elements in the transformation and qualification of health practices developed in the care of patients with COVID-19.

Evidence indicates that strengthening collaborative interprofessional practice is a prerequisite for coping with complex problems, positively impacting professional practice and the quality of comprehensive health care during the first year of the pandemic. Previous interprofessional experiences supported the restructuring of health services in a more peaceful and efficient way, improving the capacity to organize and face the crisis, improving health indicators, minimizing the incidence of adverse events and, consequently, improving the quality of health care aimed at patients with COVID-19 $9^{(3-14)}$.

\section{Interprofessional Collaboration}

The term collaboration is applied in different contexts and over time there have been many theoretical constructs around a definition consistent with its complexity. Although the diversity of contributions is recognized, studies demonstrate important reflections on the importance of collaboration and claim that there is no clarity about its complexity. In this sense, it presents fundamental principles of collaboration: sharing, partnership, interdependence and power ${ }^{(22)}$. Sharing, partnership and interdependence appeared in different ways in this review, indicating the need to reorient health practices towards a more integrated, resolute and safe perspective.

Interprofessional collaboration is, therefore, a practice in which different health professionals work guided by the aforementioned principles of collaboration, to offer more effective, comprehensive and safer health care. Health work is marked by several variables, such as time pressure, shortage of health professionals and increasingly complex health needs. In this context, it is essential that health professionals are able and committed to working in collaboration with different health professionals, with other health teams and/or sectors of society ${ }^{(22-23)}$.

The articles analyzed showed efforts in the development of collaborative skills with the scope of offering health care in the face of the complexity of the pandemic context. Communication, user centrality, shared decision-making appeared as the most prominent in the analyzed works. As a way to support this debate, there are four matrices of collaborative skills in the world: the British, which initially defines as capabilities, the Canadian, the North American and, more recently, the Australian ${ }^{(23)}$. They are important references to invest in a new logic of health work.

Interprofessional collaboration is, therefore, a premise of interprofessional teams that improves problem-solving capacity, assists in shared decision-making, facilitates efficient patient care and improves clinical results. The high degree of understanding of the roles and skills of each other among team members, develop mutual respect, cooperation, autonomy and trust, acting with a common goal ${ }^{(24)}$. These were aspects invested in the experiences reported and that gave important results in the strategies to face the COVID-19 pandemic in the different realities of the world.

\section{Collaborative Practice}

Collaborative practice is another important definition to understand the many changes in the health work dynamics in facing the COVID-19 pandemic. It happens when healthcare professionals from different professional backgrounds work together with patients, families, caregivers and communities to provide the highest quality of care. This allows health professionals to involve patients, families and communities in the production of health services, as a way to contribute to achieving health goals ${ }^{(25)}$.

To broaden this debate, the definition of collaborative practice has been associated with an intense communication process so that the sharing of goals and achievement of objectives can happen. In this sense, the relational dimension is indicated as a premise for collaborative practice. Practice integration, mediated by collaboration and with intense user participation, requires trust and mutual respect. This communication is a complex relationship that transcends the relationships between professionals and takes place between different sectors or services of a health care network ${ }^{(26)}$. These were also aspects mentioned in the analyzed studies and that reverberated in improvement of the quality of health care. Coping with complex problems such as those arising from the COVID-19 pandemic was largely successful due to the ordering of health practices based on subjects' needs, making it possible to perceive the relevance of interprofessionality ${ }^{(27)}$. In a scenario of many uncertainties, communication and horizontal relationships were essential for safe and quality care.

The fluid communication developed in the studies analyzed are recognized as essential elements for safe and high-quality care, which ensure more integrated approaches and clarity of health needs and behaviors. This logic ensures greater capacity in dealing with complex problems, adopting interventions aimed at the process and relational aspects of comprehensive health care ${ }^{(28)}$.

An example that can be mentioned is the experience of a hospital in the United States (USA) that invested in the integration of different health professionals and hospital management to share responsibility and decision-making in this critical period. Communication facilitated the interprofessional approach between all team members and other professionals in the institution, who were not necessarily involved in direct patient care. As the team arrangement moved through the units and interacted with other service professionals, communication and collaboration were expanded and facilitated in the work environment, directly reflecting on the quality of care and on the level of satisfaction of these professionals and users ${ }^{(5)}$.

\section{INTERPROFESSIONAL WORK}

Regarding interprofessional work, the reality of insecurity, fear and vulnerability that plagued health services and the entire world population, highlighted the weaknesses and limits of action of health professionals in times of crisis. Interprofessional work, in turn, proved capable of strengthening integration, articulation and collaboration among all those involved. Interprofessionalism played a strategic role in health care, allowing the creation of a more welcoming environment in which all professionals are co-responsible for the care in a comprehensive way, minimizing damage, risks and adverse events, in addition to ensuring the development of care $\operatorname{safer}^{(12-13)}$. 
This work organization calls into question the hegemonic and hierarchical model of health practices, promoting comprehensive care based on collaborative and integrated practices that improve the health system efficiency, patient and health professional satisfaction ${ }^{(29)}$. Studies in Canada ${ }^{(14)}$ also identified a reduction in rates of illness and death in the elderly population after expanding the work of interdisciplinary teams and collaboration with other health and education services.

The debate on interprofessional work is also marked by important efforts to summarize the many existing concepts. An important Brazilian study revisits essential concepts for understanding the dimensions that make up interprofessional work based on the debate on teamwork, bringing contributions from different authors demonstrates the different definitions of teamwork, justifying its need in the current context marked by the intense complexity of health needs. Teamwork, as one of the types of interprofessional work, is characterized by intense interaction, based on interprofessional communication, common goals, recognition of the work of other team members, interdependence of actions, interprofessional collaboration and user-centered care $^{(30)}$.

Another important study presents a typology of interprofessional work based on the following attributes: (1) shared commitment; (2) shared team identity; (3) clear goals; (4) clear team roles and responsibilities; (5) interdependence among team members; (6) integration between practices. Regarding this typology, networking is noteworthy, which was also identified in the studies selected in this study. In networking, team shared identity, clarity of roles/goals, interdependence, integration, and shared responsibility are less essential ${ }^{(31)}$. Several examples of networking were successful in the COVID-19 pandemic because of collaboration and communication between different health services, which were strengthened to improve the quality of services and reduce severity and mortality.

The speed with which the SARS-CoV-2 pandemic spread throughout the world, made urgent the need for readaptation and reorganization of hospitals to ensure safe care to the population. The seriousness of the cases and the lack of evidence for treatment required a quick response from health organizations to qualify the workforce and ensure effective and resolute care for people with COVID-19 ${ }^{(16-32)}$. Many hospitals have invested in building and strengthening different forms of interprofessional work to fight the pandemic through the integration of different scopes of health practices and services.

A collaboration between health services, the sharing of experiences between institutions and professionals was recognized as a catalyst to improve patient care and ensure patient safety. In the study ${ }^{(19)}$, the experience of the debriefing program, based on the Web and present in trauma hospitals in the USA evidences the expansion of responsiveness and organization based on shared experiences during the pandemic. Participants reported on the processes and protocols that were working, in addition to suggesting solutions to problems encountered. The program reinforced communication and interprofessional support, instigating significant changes in the clinical process, breaking and creating safety protocols ${ }^{(19)}$.

It is important to highlight the need for collaboration between all services in the health care network for an articulated and comprehensive care. However, the scarcity of studies in PHC demonstrates the lack of leading role of this service during the COVID-19 pandemic. Although PHC is not directly related to the intensive care of patients with COVID-19, it is shown to be potent in preventing contamination, decreasing incidence rates, follow-up of suspected and/or confirmed cases, encouragement to adhere to social distancing, among various tasks necessary to fight the pandemic ${ }^{(14-31)}$. It could be used as a key service and care coordinator, fulfilling its role of prevention and health promotion, acting collaboratively with other services in the care network, strengthening this line of care, reducing the burden of medium and high complexity services and improving the quality of comprehensive health care.

\section{Interprofessional and Collaborative Learning}

Given the essential characteristics for hospitals that care for patients affected or at risk of contamination by COVID-19(2), the studies also highlighted the need for qualification of professionals who work on the front line for fighting COVID-19. Numerous countries constituted a "task force" to train professionals who worked in direct and indirect care for patients with COVID-19 or at risk of contamination, organizing themselves to provide comprehensive and quality care. Changes in the epidemiological scenario and new health needs, associated with the criticality of patients' clinical condition and demand for relocation of professionals, require the strengthening of skills for effective teamwork ${ }^{(13-17)}$.

Interprofessional education proved to be relevant during the COVID-19 pandemic and strategic in the transformation and strengthening of health practice ${ }^{(11)}$, it contributes to the development of skills capable of improving the quality and comprehensiveness of care as well as patient safety. Some studies ${ }^{(1)}$ reiterate the need for collaboration between the various services involved in health care in relation to the training process of their professionals, from a perspective of in-service training. These are experiences that guarantee training and support to professionals in order to reduce the incidence of COVID-19 in contexts of high contamination and vulnerability.

The selected study, which brings the Brazilian experience, showed interprofessional education as an instrument for qualifying the health team in the care provided to critically ill patients with COVID-19, reiterating the importance of inter-team meetings to improve the skills needed by professionals in the care of patients with COVID-19, with emphasis on orotracheal intubation ${ }^{(6)}$.

Regarding methodologies, simulation-based education is a widely used modality in the health field to promote knowledge and develop collaborative skills, carried out in real clinical environments and by interprofessional teams that identify their difficulties and strategies to improve them. The methodology can be of high or low risk that are viewed differently by each professional, but who, acting together, learn about their role and that of the other in the team ${ }^{(31)}$.

Services that invested in structuring interprofessional learning initiatives were able to diversify care, allowing professionals to work in different sectors in the hospital unit and expanding beds for the care of suspicious patients and/or COVID-19(18). 
On the other hand, the lack of qualification of health professionals associated with the lack of information, protocols, treatments and structure in health services increased the difficulties in facing the COVID-19 pandemic.

In this category, it is important to consider, however, that interprofessional education initiatives need to explicitly express the intention to develop collaborative interprofessional skills and that these can translate into the transformation of health services and the improvement of their results. Although studies indicate the implications for health services, further studies are needed to clarify the contributions of IHE initiatives in strengthening health services and systems.

As implications for the practice of care and health, it is identified that the interprofessional work developed during the pandemic made possible the possibility of collective work, based on the needs that appeared on the world stage quickly and resolutely, in addition to viewing the growing importance of (re)situating training and practices for a more integrated, collaborative and secure look. Thus, the importance of interdisciplinarity and interprofessional education in the response to combat the pandemic is highlighted.

This review demonstrates the strengthening of interprofessional work as an indicator of improvement in the quality of services. One cannot deny the advances and agility in the responses in a short period of time in several countries during the pandemic. It became evident and apparent that the interprofessional collaborative practice, at any level of care, constituted the best way that health systems could successfully respond to the challenge of COVID-19(27).

\section{LIMITATION}

This study had as limitations the fact that it analyzed studies in Portuguese, English and Spanish, which made it impossible to analyze other studies, mainly from countries with vast experience in dealing with COVID-19 and interprofessional practices, such as the case of China, a developed country in that the pandemic started. In addition to this, there was a lack of research with a high level of evidence, such as clinical trials and studies with large samples, justified by being a recent theme. It is noteworthy that, because the pandemic is still in effect, it makes it difficult to produce reviews, as new studies are constantly being produced.

\section{CONCLUSION}

The pandemic demanded quick and effective responses that were only possible through collaboration and interprofessionalism dimensions. The mapping of scientific production related to interprofessional work in health during the first year of the COVID-19 pandemic confirms the importance of interprofessionality and its dimensions for the provision of more comprehensive, resolute and safer health services.

Institutions that reorganized themselves from an interprofessional perspective, managed to act with greater agility and clinical responsiveness, developing a more qualified assistance and offering training to health professionals who worked on the front lines, ensuring a safe and damage-free assistance for the other and for themselves.

As for scientific relevance, this study contributes in an attempt to meet the need for scientific deepening on the object of study, examining emerging evidence. As a social contribution, the study provides information that supports the improvement of work processes in health and nursing, helping to strengthen a practice in comprehensive and quality health. It is recommended for future research to carry out a systematic review on the subject and research that address the issue in PHC.

\section{RESUMO}

Objetivo: mapear a produção científica sobre relações interprofissionais em saúde no primeiro ano da pandemia de COVID-19. Método: revisão de escopo, realizada nas bases PubMed, Scopus, LILACS, CINAHL, Web of Science, Google Scholar e Science Direct, abrangendo o período de publicação do ano de 2020, utilizando o acrônimo PCC (População = profissionais de saúde; Conceito = relações interprofissionais; Contexto = serviços de saúde) e respectivas estratégias de busca. Resultados: foram selecionados 14 artigos científicos e o conteúdo discutido nos manuscritos foi uniformizado, analisado e organizado em categorias de afinidades e semelhanças de seus resultados: 1 - Colaboração interprofissional; 2 - Prática colaborativa; 3 - Trabalho interprofissional; 4 - Aprendizagem interativa e interprofissional. Conclusão: a pandemia demandou respostas rápidas e eficazes que só foram possíveis através das dimensões da colaboração e da interprofissionalidade. O trabalho interprofissional em saúde durante o primeiro ano de pandemia de COVID-19 confirma a importância do trabalho interprofissional e suas dimensões para a oferta de serviços de saúde mais integrais, resolutivos e seguros.

\section{DESCRITORES}

Relações Interprofissionais; Pessoal de Saúde; Pandemias; Infecções por Coronavirus; Gestão de Recursos da Equipe de Assistência à Saúde.

\section{RESUMEN}

Objetivo: mapear la producción científica sobre las relaciones interprofesionales en salud en el primer año de la pandemia del COVID-19. Método: revisión del alcance, realizada en las bases de datos PubMed, Scopus, LILACS, CINAHL, Web of Science, Google Scholar y Science Direct, cubriendo el período de publicación 2020, utilizando las siglas del PCC (Población = profesionales de la salud; Concepto = relaciones interprofesionales; Contexto $=$ salud servicios) y las respectivas estrategias de búsqueda. Resultados: se seleccionaron 14 artículos científicos y el contenido discutido en los manuscritos fue estandarizado, analizado y organizado en categorías de afinidades y similitudes de sus resultados: 1 - Colaboración interprofesional; 2 - Práctica colaborativa; 3 - Trabajo interprofesional; 4 - Aprendizaje interactivo e interprofesional. Conclusión: la pandemia exigía respuestas rápidas y eficaces que solo eran posibles a través de las dimensiones de la colaboración y la interprofesionalidad. El trabajo interprofesional en salud durante el primer año de la pandemia COVID-19 confirma la importancia del trabajo interprofesional y sus dimensiones para la prestación de servicios de salud más integrales, decididos y seguros.

\section{DESCRIPTORES}

Relaciones Interprofesionales; Personal de Salud; Pandemias; Infecciones por Coronavirus; Gestión de Recursos de Personal en Salud. 


\section{REFERENCES}

1. Lingum NR, Sokoloff LG, Meyer RM, Gingrich S, Sodums DJ, Santiago AT, et al. Building long-term care staff capacity during COVID-19 through just-in-time learning: evaluation of a modified ECHO model. J Am Med Dir Assoc. 2020;22(2):238-44.E1. DOI: https://doi.org/10.1016/j. jamda.2020.10.039.

2. Noce LGA, Oliveira TS, Melo LC, Silva KFB, Parreira BDM, Goulart BF. Interprofessional relationships of a patient care team in critical care. Rev Bras Enferm. 2020;73(4):e20190420. DOI: https://doi.org/10.1590/0034-7167-2019-0420.

3. Santos GLA, Valadares GV, Santos SS, Moraes CRBM, Mello JCM, Vidal LLS. Interprofessional collaborative practice and nursing care. Escola Anna Nery. 2020;24(3):e20190277. DOI: https://doi.org/10.1590/2177-9465-EAN-2019-0277.

4. Sarver WL, Seabold K, Kline M. Shadowing to Improve Teamwork and Communication: A Potential Strategy for Surge Staffing. Nurse Lead. 2020;18(6):597-603. DOI: https://doi.org/10.1016/j.mnl.2020.05.010.

5. Stifter J, Terry A, Phillips J, Heitschmidt M. A short report on an interprofessional mobilizer team: innovation and impact during the COVID-19 pandemic. J Interprof Care. 2020;34(5):716-8. DOI: https://doi.org/10.1080/13561820.2020.1813696.

6. Belarmino AC, Rodrigues MENG, Anjos SJSB, Ferreira Júnior AR. Collaborative practices in health teams in the face of the COVID-19 pandemic. Rev Bras Enferm. 2020;73(2 Suppl):e20200470. DOI: https://doi.org/10.1590/0034-7167-2020-0470.

7. Peters MDJ, Godfrey C, Mclnerney P, Munn Z, Tricco AC, Khalil, H. Chapter 11: Scoping Reviews (2020 version). In: Aromataris E, Munn Z, editors. JBI Manual for Evidence Synthesis. Adelaide: JBI; 2020.

8. Arksey H, O'malley L. Scoping studies: towards a methodological framework. Int J Soc Res Methodol. 2005;8(1):19-32. DOI: https://doi.org/10. 1080/1364557032000119616.

9. Tricco AC, Lillie E, Zarin W, O'Brien KK, Colquhoun H, Levac D, et al. PRISMA extension for scoping reviews (PRISMA-ScR): checklist and explanation. Ann Intern Med. 2018;169(7):467-73. DOI: https://doi.org/10.7326/M18-0850.

10. Rethlefsen ML, Kirtley S, Waffenschmidt S, Ayala AP, Moher D, Page MJ, et al. PRISMA-S: an extension to the PRISMA Statement for Reporting Literature Searches in Systematic Reviews. Syst Rev. 2021;10:39. DOI: https://doi.org/10.1186/s13643-020-01542-z.

11. Khan JA, Kiani MRB. Impact of multi-professional simulation-based training on perceptions of safety and preparedness among health workers caring for coronavirus disease 2019 patients in Pakistan. J Educ Eval Health Prof. 2020;17:19. DOI: https://doi.org/10.3352/jeehp.2020.17.19.

12. Archbald-Pannone LR, Harris DA, Albero K, Steele RL, Pannone AF, Mutter JB. COVID-19 collaborative model for an academic hospital and longterm care facilities. J Am Med Dir Assoc. 2020;21(7):939-42. DOI: https://doi.org/10.1016/j.jamda.2020.05.044.

13. Sarver WL, Seabold K, Kline M. Shadowing to Improve Teamwork and Communication: A Potential Strategy for Surge Staffing. Nurse Lead. 2020;18(6):597-603. DOI: https://doi.org/10.1016/j.mnl.2020.05.010.

14. Meisner BA, Boscart V, Gaudreau P, Stolee P, Ebert P, Heyer M, et al. Interdisciplinary and Collaborative Approaches Needed to Determine Impact of Covid-19 on Older Adults and Aging: CAG/ACG and CJA/RCV Joint Statement. Can J Aging. 2020;39:(3):1-31. DOI: https://doi.org/10.1017/ S0714980820000203.

15. Natale JE, Boehmer J, Blumberg DA, Dimitriades C, Hirose S, Kair LR, et al. Interprofessional/interdisciplinary teamwork during the early COVID-19 pandemic: experience from a children's hospital within an academic health center. J Interprof Care. 2020;34(5):682-6. DOI: https://doi.org/10. 1080/13561820.2020.1791809.

16. Hales P, White A, Eden A, Hurst R, Moore S, Riotto C, et al. A case study of a collaborative allied health and nursing crisis response. J Interprof Care. 2020;34(5):614-21. DOI: https://doi.org/10.1080/13561820.2020.1813093.

17. Goldman J, Xyrichis A. Interprofessional working during the COVID-19 pandemic: sociological insights. J Interprof Care. 2020;34(5):580-2. DOI: https://doi.org/10.1080/13561820.2020.1806220.

18. Carenzo L, Costantini E, Greco M, Barra FL, Rendiniello V, Mainetti M, et al. Hospital surge capacity in a tertiary emergency referral centre during the COVID-19 outbreak in Italy. Anaesthesia. 2020;75(7):928-34. DOI: https://doi.org/10.1111/anae.15072.

19. Azizoddin DR, Gray KV, Dundin A, Szyld D. Bolstering clinician resilience through an interprofessional, web-based nightly debriefing program for emergency departments during the COVID-19 pandemic. J Interprof Care. 2020;34(5):711-5. DOI: https://doi.org/10.1080/13561820.2020. 1813697.

20. Tronnier A, Mulcahy CF, Pierce A, Benjenk I, Sherman M, Heinz ER, et al. COVID-19 Intubation Safety: A Multidisciplinary, Rapid-Cycle Model of Improvement. Am J Med Qual. 2020;35(6):450-7. DOI: https://doi.org/10.1177/1062860620949141.

21. Caneppele AH, Cucolo DF, Miniel VA, Meireles E, Silva JAM. Interprofessional collaboration in urgency and emergency network teams in the Covid-19 pandemic. Escola Anna Nery. 2020;24(Spe):e20200312. DOI: https://doi.org/10.1590/2177-9465-EAN-2020-0312.

22. Bainbridge L, Nasmith L, Orchard C, Wood V. Competencies for Interprofessional Collaboration. J Phys Ther Educ. 2010;24(1):6-11. DOI: https:// doi.org/10.1097/00001416-201010000-00003.

23. Thistlethwaite JE, Forman D, Matthews LR, Rogers GD, Steketee C, Yassine T. Competencies and frameworks in interprofessional education: a comparative analysis. Acad Med. 2014;89(6):869-75. DOI: https://doi.org/10.1097/acm.0000000000000249.

24. Ansa BE, Zechariah S, Gates AM, Johnson SW, Heboyan V, De Leo G. Attitudes and Behavior towards Interprofessional Collaboration among Healthcare Professionals in a Large Academic Medical Center. Healthcare. 2020;8(3):323. DOI: https://doi.org/10.3390/healthcare8030323.

25. World Health Organization. Framework for action on interprofessional education \& collaborative practice. Geneva: WHO; 2010.

26. Gittell JH, Godfrey M, Thistlethwaite J. Interprofessional collaborative practice and relational coordination: Improving healthcare through relationships. J Interprof Care. 2013;27(3):210-3. DOI: https://doi.org/10.3109/13561820.2012.730564.

27. Xyrichis A, Williams U. Strengthening health systems response to COVID-19: interprofessional science rising to the challenge. J Interprof Care. 2020;34:(5):577-9. DOI: https://doi.org/10.1080/13561820.2020.1829037. 
28. McHugh SK, Lawton R, O'Hara JK, Sheard L. Does team reflexivity impact teamwork and communication in interprofessional hospital-based healthcare teams? A systematic review and narrative synthesis. BMJ Qual Saf. 2020;29(8):672-83. DOI: https://doi.org/10.1136/bmjqs-2019-009921.

29. Sibbald S, Schouten K, Sedig K, Maskell R, Licskai C. Key characteristics and critical junctures for successful Interprofessional networks in healthcare a case study. BMC Health Serv Res. 2020;20(1):700. DOI: https://doi.org/10.1186/s12913-020-05565-z.

30. Peduzzi M, Agreli HLF, Silva JAM, Souza HS. Teamwork: Revisiting the concept and its developments in inter-professional work. Trabalho, educação e saúde. 2020;18 Suppl 1:1-20. DOI: https://doi.org/10.1590/1981-7746-sol00246.

31. Reeves S, Lewin S, Espin S, Zwarenstein M. Interprofessional teamwork for health and social care. Sussex: Wiley-Blackwell; 2010.

32. Daumas RP, Silva GA, Tasca R, Leite IC, Brasil P, Greco DB, et al. The role of primary care in the health care network in Brazil: limits and possibilities in coping with COVID-19. Cad Saude Publica. 2020;36(6):e00104120. DOI: https://doi.org/10.1590/0102-311X00104120. 